\title{
The Body Mass Index and Menstrual Problems among Adolescent Students
}

\author{
Dr. Nabila Hassan Ali Abdella ${ }^{1}$, Dr. Elsayda Hamdy Nasr Abd-Elhalim², \\ Dr. Azza Mohamed Fathy Attia ${ }^{3}$ \\ ${ }^{1,3}$ Lecturer of Pediatric Nursing, Faculty of Nursing, Port-said University. \\ ${ }^{2}$ Lecturer of Maternity, Gynecological and Obstetrics Nursing, Faculty of Nursing, Port-said University.
}

\begin{abstract}
Menstruation is an important part of female reproductive cycle but menstrual problems in adolescent girls may affect normal life of adolescent and young adult women. Many factors play a role in regularity and flow of menstrual cycle, which include hormonal changes, genetics and body mass index (BMI).

Objective: Objective was to assess the relationship between body mass index and menstrual problems.

Design: the current study was a cross sectional study carried out between October 2014 to April 2015.

Setting: The study was conducted in four governmental secondary and preparatory schools, which represent one district of Port Said City, together with the Faculty of nursing at Port-Said, Egypt. A purposive sample of 366 female students who attained menarche was selected from the above-mentioned settings.

Results: The mean age of the girls was 14.9 years and more than two thirds (66.7\%) had regular menstrual cycle, while $33.3 \%$ of them had irregular menstrual cycle. The majority of the sample (82.8\%) complained of premenstrual symptoms. As regards BMI ranged between 18.3 - $33.9 \mathrm{kgandcm} 2$, 53.8\% had normal weight, while 33.9\%, 12.0\% were overweight \& obese. Relationship between BMI and menstrual problems. A statistically significant relationship was found between BMI menstrual irregularity $(P=0.0001)$ and BMI and severity of premenstrual symptoms excess body hair ( $P=0.007,0.03$ respectively).

Conclusions: Based on the result current study concluded that, BMI play a very important role for menstrual cycle regularity. Therefore, adolescents have to give healthy \& balance nutrition leads to maintain the normal $B M I$ and regulate their menstrual cycle. The body weight and socio economic status has significant relation with menstrual problems.

Recommendations: lifestyle modification and nutritional counseling for female students could alleviate menstrual problems. It will not only improve the girls current health, sense of well-being and overall quality of life but may also lower her risks for future disease and ill health after proper advice about diet and exercise, further research in nutritional pattern in adolescents can be done.
\end{abstract}

Keywords: BMI, Menstrual problems, Adolescents female.

\section{Introduction}

Menstruation occurs once a month as a regular rhythmic period and remains as a normal physiological phenomenon from menarche to menopause. It is regulated by cyclical changes in female sex hormones and regularity of menstrual cycles reflects changes in the level of these hormones (1). Menarche is the first menstrual period; it is generally occurring between 11-15 years. It is the time when there are sudden changes in their body and the changes bring along problems with them. The most challenging problems are related to menstruation; in girls (2).

Factors that often play a role in the regularity and flow of a woman's menstrual cycle include hormonal changes, genetics, serious medical conditions and BMI. Moreover, psychological well-being is known to influence the age of menarche and common menstrual problems $(3,4)$.

Menstrual problems include; menstrual cycle irregularities (of duration or length), hyper- or hypomenorrhoea, poly- or oligomenorrhoea, dysmenorrhoea, amenorrhoea, menorrhagia and premenstrual syndrome (5). They affect the quality of life of adolescents and young adult women, especially those who suffer dysmenorrhea and heavy menstruation. The World Health Organization reports that 18 million women aged 3055 years perceive their menstrual bleeding to be excessive (6). A high proportion of women in other studies reported suffering oligomenorrhoea or amenorrhoea and these have been associated with BMI (7) and other complications such as polycystic ovary syndrome (PCOS), hirsutism or infertility (3). Moreover, Dars et al., $2014{ }^{(8)}$, cross sectional study on Relationship of Menstrual Irregularities to BMI and nutritional status in adolescent girls", found that 75.5\% girls with BMI 14-24.9 had a normal menstrual pattern. All sixteen girls with a BMI of $25-29.9 \mathrm{~kg} / \mathrm{m} 2$ had infrequent cycles. A statistically significant relationship was observed between BMI and menstrual pattern. According to WHO the BMI of age group 12 to 17 years old has raised 
from $5.7 \%$ on 2009 to $11.1 \%$ on 2011 around the world, this had profound impact on female reproductive health (9).

Menstrual problems are generally perceived as only minor health concern and thus irrelevant to the public health agenda particularly for women in developing countries who may face life-threatening conditions. Although they are diagnosable and mostly treatable even at peripheral level in early stage, they are often ignored by primary health care in most of the developing countries (10) Such disorders also have economic consequences in terms of health care costs due to the consumption of expensive hormonal drugs and laboratory tests ( 11).

\section{I.1.Significance of the study:}

Menstrual health is fundamental to women's sexual and reproductive health. Identification of abnormal menstrual patterns through adolescence by a nurse midwife may permit early identification of potential health concerns for adulthood. It is, therefore, necessary to clarify what factors are associated with menstrual irregularities in order to assist in improving their quality of life. Moreover, her effort in counseling adolescent females about weight reduction can be effective in alleviating the menstrual disturbances. Given the rising prevalence of overweight and obesity in Port Said, it is important to investigate their effects on female's reproductive health and to better quantify the strength of association with menstrual problems in adolescent sample.

\section{Aim of the Study}

The aim of this study is to assess the relationship between Body Mass Index and Menstrual Problems among adolescent girls.

\section{Subjects and Methods}

3. 1 Research design: A case-control design was adopted in this study.

3. 2 Setting: The present study was conducted at Port Said governmental secondary and preparatory schools for girls and Faculty of Nursing in Port Said City.

3. 3 Subjects: A purposive sample of 366 female students was selected for this study. Students were eligible for recruitment in the study if they met the following inclusion criteria:

1. Adolescent females.

2. Age ranging from $12-18$ years.

3. Free from abnormal puberty.

4. The student is not pregnant or breastfeeding Any deviation from these criteria was excluded.

3. 4 Sampling Size:

Since the prevalence of adolescent females in Port Said City was $13.7 \%$ as reported by Agency of Public Mobilization and Statistical (CAPMAS, 2012 (12), this substituting in the following equation:

Sample Size $(n)=\frac{Z(P q)^{2}}{--d^{2}}$

Where:

Z: 1.96

P: Prevalence of adolescent females

q: $(1-13.7)(1-P)$

d: Is width of the desired sample confidence interval $=0.098$

$\mathbf{d}^{2}: 0.00960$

$\mathbf{n}: \mathbf{3 6 6}$ adolescent females

\section{5 Tools of Data Collection:}

A self-administered, structured, anonymous questionnaire was designed for the study.

The questionnaire covered information about the following demographic variables: age, marital status, residence and presence of pregnancy and breastfeeding (to rule out the cause of amenorrhea if present).The participants were then asked about the characteristics of their menstruation: age of menarche, regularity/irregularity of menstruation in interval and duration; amount of blood loss (number of pads used); pain during menstruation and degree and location of pain; activity during menstruation; symptoms of PMS, whether the symptoms disappear after menstruation. 


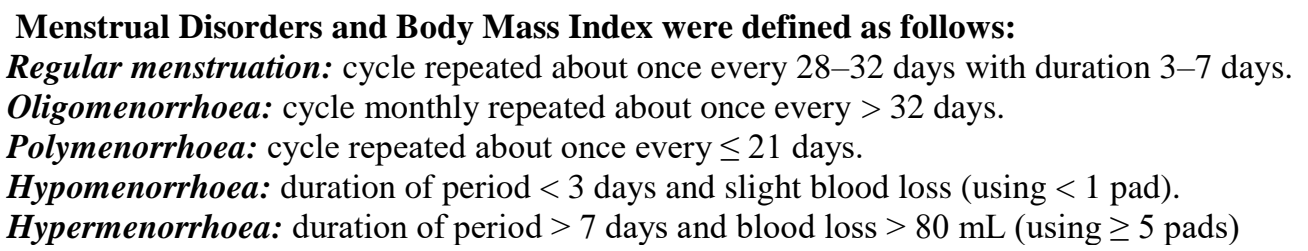

Premenstrual Menstrual syndrome (PMS): are the cyclic recurrence of physiological behavioral or somatic symptom. They start few days premenstrual and relieved by the onset of menstruation. They include; nervous and gastrointestinal symptoms, edema, weight gain and breast symptoms. $(13,14)$.

Weight: was measured in kilogram, without footwear using a regularly standardized beam balance. Checks on the scale were made routinely before recording the weight of each girl. Height: was also taken barefooted in centimeter using standard measuring tape fixed vertically. It was recorded to the nearest $1 \mathrm{~cm}$ to avoid possible error.

Body Mass Index (BMI): was calculated as weight in $\mathrm{kg} / \mathrm{height}$ in $\mathrm{m} 2$. According to BMI, nutritional status was classified as overweight (over nourished), normal and undernourished as BMI more > 25, 18.5-24.99 and < $18.5 \mathrm{~kg} /$ height in $\mathrm{m} 2$ respectively $(\mathbf{1 5}, \mathbf{1 6})$.

\section{a. Validity and Reliability}

Tool was reviewed by a panel of five experts in the field of Obstetrics and Gynecological Nursing to test its content validity. Modifications were done accordingly based on their judgment. Confirming the stability of the questionnaire, Cronbach's alpha was used because it gives the minimum reliability coefficient scale, beside it does not require reapplication, and it has been shown that the Cronbach's alpha coefficient equal to 0.0653 is an excellent factor in such study.

\section{b. Administrative and ethical consideration}

An official permission was granted by submission of an official letter from the Faculty of Nursing to the responsible authorities of the study setting to obtain their permission for data collection. All ethical issues were taken into consideration during all phases of the study; the researcher maintained an anonymity and confidentiality of the subjects. The inclusion in the study was totally voluntary. The aim of the study was explained to every student before participation, oral consent was obtained from every student prior to data collection. Students were assured that the study maneuver would cause no actual or potential harm to her. Also, they were assured that professional help will be provided for them whenever needed. Students were notified that they can withdraw at any stage of the research.

\section{8 Pilot study:}

A pilot study was carried out on $10 \%$ of the sample (who were excluded from the sample) to assess the clarity and applicability of the data collection tools, arrangements of items, estimate the time needed for each sheet and the feasibility of the study and acceptance to be involved in the study. Necessary modifications were undertaken.

\section{9 Field study:}

Collection of data covered a period of six months from October 2014 to April 2015. The researcher attended the above-mentioned setting on three days (Saturday, Monday, and Wednesday) per week; the tool was self-answered. The time needed by the researcher for the completion of the questionnaire sheet was ranged from 20-30 minutes, girls interviewed ranged between 1 to 6 students per day.

\section{10 Statistical design:}

Data entry and analysis were done using the statistical package for social science (SPSS), version 16.0. Quality control was done at the stages of coding and data entry. Data were presented using descriptive statistics in the form of frequencies and percentages for qualitative variables, and means and standard deviations, chisquare and p-value for quantitative variables.

\section{Results}

The results obtained from the current study are categorized as follows: demographic characteristics; menstrual characteristics; premenstrual syndrome; pattern of body mass index. In addition, the relationship 
between BMI and menstrual problem. The findings of the present study gathered were tabulated, analyzed and interpreted using both descriptive and inferential statistics.

Table (1): Distribution of the studied group according to their demographic characteristics $(\mathrm{n}=366)$

\begin{tabular}{|l|l|l|}
\hline Characteristics & No. & \% \\
\hline Age (years) & \multicolumn{2}{|l|}{} \\
\hline $12-$ & 159 & 43.4 \\
\hline $15-18$ & 207 & 56.6 \\
\hline Min. - Max. & $12.0-18.0$ \\
\hline Mean \pm SD & $14.9 \pm 2.1$ \\
\hline Family income (L.E.) & \multicolumn{2}{|l}{} \\
\hline Sufficient & 157 & 42.9 \\
\hline Insufficient & 209 & 57.1 \\
\hline Crowding index: & 361 & 98.6 \\
crowded & 5 & 1.4 \\
not crowded & $2-5$ & \\
\hline Min-Max & $2.4 \pm 1.01$ & \\
Mean \pm SD & \multicolumn{2}{|l}{} \\
\hline
\end{tabular}

Table 1: shows that more than half of the students were 15 years old and more $(56.6 \%)$ with a mean of $14.9 \pm 2.1$ years. Meanwhile, they mostly had insufficient income and living in crowded homes.

Figure (1): Distribution of the studied sample according to the pattern of menstruation

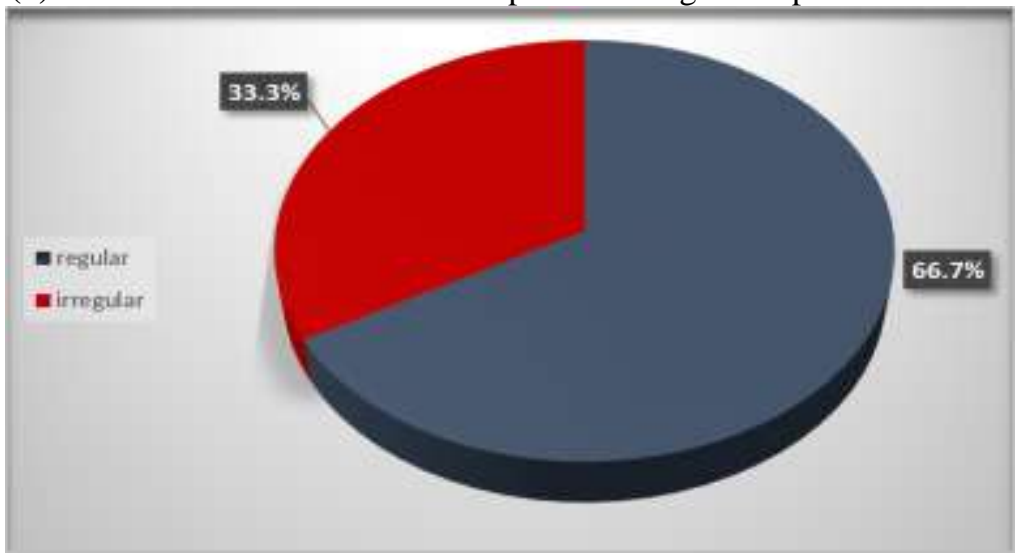

Figure 1: demonstrates that out of 366 adolescents $244(66.7 \%)$ had regular and $122(33.3 \%)$ girls had irregular menstrual cycles.

Table (2): Distribution of the studied group according to their menstrual characteristics $(\mathrm{n}=366)$

\begin{tabular}{|l|l|l|}
\hline Items & No. & \% \\
\hline Age of menarche & & \\
\hline $9-11$ & 101 & 27.6 \\
\hline $11-<14$ & 230 & 62.8 \\
\hline Don't know & 35 & 9.6 \\
\hline Regularity of menstrual cycle & & \\
\hline Regular & 244 & 66.7 \\
\hline Irregular & 122 & 33.3 \\
\hline @Irregularity of menstrual cycle (N= 122) & & \\
\hline$\bullet \quad$ Excessive Amount of menstrual blood flow & 20 & 16.3 \\
\hline$\bullet \quad$ Little Amount of menstrual blood flow & 55 & 45.0 \\
\hline$\bullet \quad$ Long Duration of menstruation & 33 & 27.0 \\
\hline$\bullet \quad$ Long interval between menstrual cycle & 32 & 26.2 \\
\hline$\bullet \quad$ Short interval between menses & 30 & 24.6 \\
\hline Number of perineal pads per day & & \\
\hline One & 52 & 14.2 \\
\hline Two & 200 & 54.6 \\
\hline Three or more & 114 & 31.2 \\
\hline Duration of menstruation(days) & & \\
\hline$<2$ & 30 & 8.2 \\
\hline $3-7 \quad$ & 262 & 71.6 \\
\hline$\geq 8 \quad 74$ & 20.2 \\
\hline
\end{tabular}

@ Students had more than one answer 
It is obvious in table 2 that lowest and highest age at menarche was below 11 and above 15 years respectively with the mean age at menarche of $12.8 \pm 1.06$ years. Meanwhile, $45.0 \%$ had little amount of menstrual blood and $16.3 \%$ had menorrhagia (profuse bleeding). Partially equal percentage of participants suffered from long duration and long interval of menstrual cycle (27.0\% and $26.2 \%$ respectively).

Table (3): Distribution of the studied adolescent girls according to their reported premenstrual syndrome

(n=366)
\begin{tabular}{|l|l|l|}
\hline Symptoms & No & $\%$ \\
\hline Premenstrual syndrome & & \\
\hline Yes & 303 & 82.8 \\
\hline No & 63 & 17.2 \\
\hline Symptoms of Premenstrual syndrome & & \\
\hline Physical symptoms: (colic-back pain-headache and exhaustion) & 172 & 56.8 \\
\hline Psychological symptoms: (anxiety- depression-nervous) & 95 & 31.4 \\
\hline Behavioral symptoms: (withdrawal-stay in home- absenteeism) & 36 & 11.9 \\
\hline Severity of Premenstrual syndrome: (n=303) & & \\
\hline Mild & 71 & 23.4 \\
\hline Moderate & 132 & 43.6 \\
\hline Sever & 100 & 33.0 \\
\hline Total & 303 & 100.0 \\
\hline
\end{tabular}

Table 3: shows that the majority of the studied students $(82.8 \%)$ were exposed to PMS. Of those, physical symptoms was the most common 172 (56. \%) followed by psychological symptoms $95(31.4 \%)$ and were severe in one third of the sample $(33.0 \%)$.

Figure (2): Distribution of the studied sample according to the pattern of their BMI

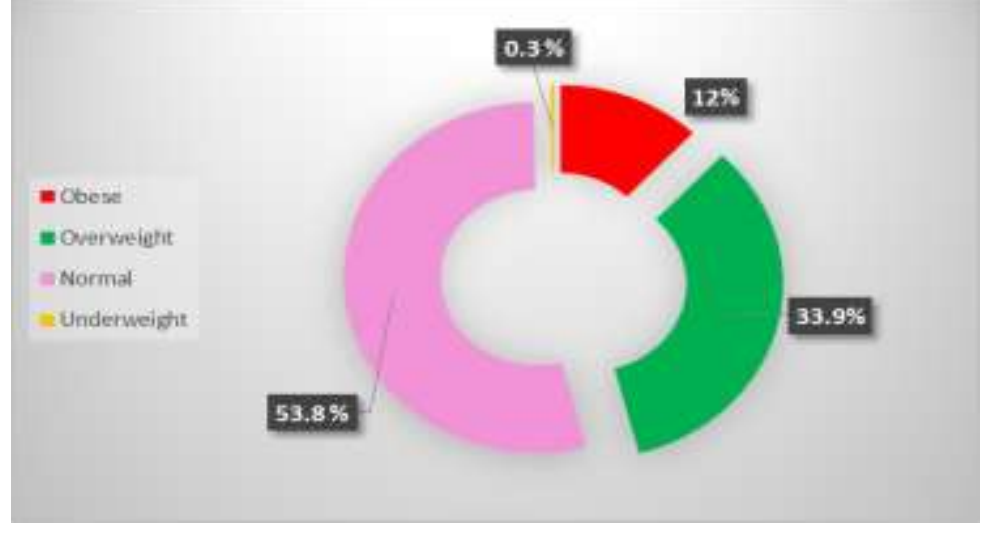

Figure 2: demonstrates that almost half of the studied adolescents were overweight and obese $(33.9 \%$ and $12.0 \%$ respectively) with a mean BMI $25.2 \pm 3.5$.

Table 4: Relationship between Characteristics of Menstruation of the studied adolescent girls and their body mass index" BMI"

\begin{tabular}{|c|c|c|c|c|c|c|c|}
\hline \multirow[t]{3}{*}{ Characteristics of Menstruation } & \multicolumn{6}{|c|}{ BMI of adolescents $(n=365)$} & \multirow[t]{3}{*}{ Significance } \\
\hline & \multicolumn{2}{|c|}{$\begin{array}{l}\text { Normal } \\
(n=197)\end{array}$} & \multicolumn{2}{|c|}{$\begin{array}{l}\text { Overweight } \\
(n=124)\end{array}$} & \multicolumn{2}{|c|}{$\begin{array}{l}\text { Obese } \\
(n=44)\end{array}$} & \\
\hline & No. & $\%$ & No. & $\%$ & No. & $\%$ & \\
\hline \multicolumn{7}{|l|}{ Age of menarche } & \multirow{4}{*}{$\begin{array}{l}X^{2}=3.570 \\
P=0.168\end{array}$} \\
\hline $9-11$ & 56 & 56.0 & 37 & 37.0 & 7 & 7.0 & \\
\hline $11-<14$ & 121 & 52.6 & 76 & 33.0 & 33 & 14.3 & \\
\hline Don't know & 20 & 57.1 & 11 & 31.4 & 4 & 11.4 & \\
\hline \multicolumn{7}{|l|}{ Regularity of menses } & \multirow{3}{*}{$\begin{array}{l}\mathrm{X}^{2}=0.985 \\
\mathrm{P}=0.01 *\end{array}$} \\
\hline Regular & 129 & 65.5 & 87 & 70.2 & 28 & 63.6 & \\
\hline Irregular & 68 & 34.5 & 37 & 29.8 & 16 & 36.4 & \\
\hline \#Type of irregularity & \multicolumn{2}{|c|}{$(n=92)$} & \multicolumn{2}{|c|}{$(n=50)$} & \multicolumn{2}{|c|}{$(n=28)$} & \\
\hline Excessive Amount of blood flow & 12 & 13.1 & 4 & 8.0 & 4 & 14.3 & $\mathrm{X}^{2}=2.6 \mathrm{P}=0.272$ \\
\hline Little amount of blood flow & 35 & 38.1 & 13 & 26.0 & 7 & 25.0 & $\mathrm{X}^{2}=2.95 \mathrm{P}=0.002 *$ \\
\hline Long Duration of menstruation & 16 & 17.4 & 13 & 26.0 & 4 & 14.3 & $\mathrm{X}^{2}=0.23 \mathrm{P}=0.022 *$ \\
\hline Long interval between menses & 19 & 20.7 & 5 & 10.0 & 8 & 28.6 & $\mathrm{X}^{2}=7.6 \mathrm{P}=0.0001^{*}$ \\
\hline Short interval between menses & 10 & 10.7 & 15 & 30.0 & 5 & 17.8 & $X^{2}=4.08 \quad P=0.001 *$ \\
\hline Frequency of changing pads per day & & & & & & & $\mathrm{X}^{2}=3.302$ \\
\hline
\end{tabular}


The Body Mass Index and Menstrual problems among Adolescent Students

\begin{tabular}{|c|c|c|c|c|c|c|c|}
\hline Once & 23 & 11.7 & 22 & 17.7 & 6 & 13.6 & \multirow[t]{3}{*}{${ }^{{ }^{\mathrm{MC}} \mathrm{P}=0.051}$} \\
\hline Twice & 115 & 58.4 & 62 & 50.0 & 23 & 52.3 & \\
\hline Three pads & 59 & 29.9 & 40 & 32.3 & 15 & 34.1 & \\
\hline Duration of menses (days) & & & & & & & \multirow{4}{*}{$\begin{array}{l}X^{2}=9.309 \\
P=0.05^{*}\end{array}$} \\
\hline Less than 2 & 19 & 9.6 & 10 & 8.1 & 1 & 2.3 & \\
\hline $3-7$ & 135 & 68.5 & 87 & 70.2 & 40 & 90.9 & \\
\hline 8 or more & 43 & 21.8 & 27 & 21.7 & 3 & 6.8 & \\
\hline
\end{tabular}

Table 4: shows relationship between BMI and menstrual problems. Students who were obese were more likely to have an excessive amount of blood flow and long interval between the menstrual period (14.3\% and $28.6 \%$ respectively), compared to those who had normal BMI (13.1\% and 20.7\% respectively). Meanwhile, students who were overweight $(30.0 \%)$ were significantly more likely to have short interval between the menstruation compared to those who had normal BMI (10.7\%). There was statistical difference between all comparisons except age of menarche and Frequency of changing pads per day.

Table 5: Relationship between Premenstrual syndrome of the studied adolescent girls and their body mass

\begin{tabular}{|c|c|c|c|c|c|c|c|c|c|}
\hline \multirow[t]{3}{*}{ Premenstrual syndrome } & \multicolumn{8}{|c|}{ BMI of adolescents (n=365) } & \multirow[t]{3}{*}{ Significance } \\
\hline & \multicolumn{2}{|c|}{$\begin{array}{ll}\text { Normal } & \text { BMI } \\
(n=197) & \end{array}$} & \multicolumn{2}{|c|}{$\begin{array}{l}\begin{array}{l}\text { Overweight } \\
(\mathbf{n}=124)\end{array} \\
\end{array}$} & \multicolumn{2}{|c|}{$\begin{array}{l}\text { Obese } \\
(n=44)\end{array}$} & \multicolumn{2}{|c|}{$\begin{array}{l}\text { Total } \\
(n=365)\end{array}$} & \\
\hline & No. & $\%$ & No. & $\%$ & No. & $\%$ & No. & $\%$ & \\
\hline \multicolumn{9}{|l|}{ Premenstrual syndrome } & \multirow{3}{*}{$\begin{array}{l}\mathrm{X}^{2}=2.252 \\
\mathrm{P}=0.324\end{array}$} \\
\hline Yes & 159 & 52.5 & 108 & 35.6 & 36 & 11.9 & 303 & 83.0 & \\
\hline No & 38 & 61.3 & 16 & 25.8 & 8 & 12.9 & 62 & 17.0 & \\
\hline $\begin{array}{l}\text { Symptoms of premenstrual } \\
\text { syndrome }\end{array}$ & \multicolumn{2}{|c|}{$[\mathrm{n}=159]$} & \multicolumn{2}{|c|}{$[\mathrm{n}=108]$} & \multicolumn{2}{|c|}{$[\mathrm{n}=36]$} & \multicolumn{2}{|c|}{$[n=303]$} & \multirow[t]{4}{*}{$\begin{array}{l}\mathrm{X}^{2}=5.455 \\
{ }^{\mathrm{MC}} \mathrm{P}=0.243\end{array}$} \\
\hline Physical symptoms & 91 & 57.2 & 55 & 50.9 & 26 & 72.2 & 172 & 56.8 & \\
\hline Psychological & 50 & 31.5 & 37 & 34.3 & 8 & 22.2 & 95 & 31.4 & \\
\hline Behavioral & 18 & 11.3 & 16 & 14.8 & 2 & 5.6 & 36 & 11.8 & \\
\hline $\begin{array}{l}\text { Severity of pre-menstrual } \\
\text { symptoms }\end{array}$ & \multicolumn{2}{|c|}{ [n=159] } & \multicolumn{2}{|c|}{$[\mathrm{n}=\mathbf{1 0 8}]$} & \multicolumn{2}{|c|}{$[\mathrm{n}=36]$} & \multicolumn{2}{|c|}{$[n=303]$} & \multirow[t]{4}{*}{$\begin{array}{l}X^{2}=14.019 \\
P=0.007 *\end{array}$} \\
\hline Mild & 31 & $\underline{19.5}$ & 37 & 34.5 & 3 & 8.4 & 71 & 23.4 & \\
\hline Moderate & 73 & $\overline{\underline{45.9}}$ & 38 & 35.0 & 21 & 58.3 & 132 & 43.6 & \\
\hline Severe & 55 & $\underline{\underline{34.6}}$ & 33 & 30.5 & 12 & 33.3 & 100 & 33.0 & \\
\hline \multicolumn{9}{|l|}{$\begin{array}{l}\text { Suffering from excess body } \\
\text { hair }\end{array}$} & \multirow[t]{3}{*}{$\begin{array}{l}X^{2}=0.352 \\
P=0.03 *\end{array}$} \\
\hline Yes & 82 & 41.6 & 50 & 40.3 & 20 & 45.5 & 152 & 41.6 & \\
\hline No & 115 & 58.4 & 74 & 59.7 & 24 & 54.5 & 213 & 58.4 & \\
\hline
\end{tabular}

Table (5): Illustrates the relationship between Premenstrual syndrome of the studied adolescent girls and their body mass index" BMI" of There was no statistical difference between Premenstrual syndrome and it's symptoms and body mass index. While, There was statistical difference between severity of premenstrual symptoms and Suffering from excess body hair $(\mathrm{P}=0.007),(\mathrm{P}=0.03)$.

Table (6): Relationship between Socio-demographic characteristics of the studied adolescent girls and their body mass index" BMI"

\begin{tabular}{|c|c|c|c|c|c|c|c|c|c|}
\hline \multirow{3}{*}{$\begin{array}{l}\text { Socio-demographic } \\
\text { characteristics }\end{array}$} & \multicolumn{8}{|c|}{ BMI of adolescents $(n=365)$} & \multirow[t]{3}{*}{ Significance } \\
\hline & \multicolumn{2}{|c|}{$\begin{array}{ll}\begin{array}{l}\text { Normal } \\
(n=197)\end{array} & \text { BMI } \\
\end{array}$} & \multicolumn{2}{|c|}{$\begin{array}{l}\text { Overweight } \\
(n=124)\end{array}$} & \multicolumn{2}{|c|}{$\begin{array}{l}\text { Obese } \\
(n=44)\end{array}$} & \multicolumn{2}{|c|}{$\begin{array}{l}\text { Total } \\
(n=365)\end{array}$} & \\
\hline & No. & $\%$ & No. & $\%$ & No. & $\%$ & No. & $\%$ & \\
\hline Age (years) & & & & & & & & & $\mathrm{F}=1.200$ \\
\hline $12-15$ & 91 & 46.2 & 52 & 41.9 & 15 & 34.1 & 158 & 43.3 & $\mathrm{P}=0.302$ \\
\hline $15-\leq 18$ & 106 & 53.8 & 72 & 58.1 & 29 & 65.9 & 207 & 56.7 & \\
\hline Min-Max & \multicolumn{6}{|c|}{$12.0-18.0$} & \multicolumn{2}{|c|}{$12.0-18.0$} & \\
\hline Mean \pm SD & \multicolumn{2}{|c|}{$14.8 \pm 2.2$} & \multicolumn{2}{|c|}{$14.9 \pm 2.2$} & \multicolumn{2}{|c|}{$15.4 \pm 2.1$} & \multicolumn{2}{|c|}{$14.9 \pm 2.2$} & \\
\hline Family income & & & & & & & & & \multirow{3}{*}{$\begin{array}{l}X^{2}=6.830 \\
P=0.033^{*}\end{array}$} \\
\hline Sufficient & 72 & 36.5 & 61 & 49.2 & 23 & 52.3 & 156 & 42.7 & \\
\hline Insufficient & 125 & 63.5 & 63 & 50.8 & 21 & 47.7 & 209 & 57.3 & \\
\hline \multicolumn{9}{|l|}{$\begin{array}{l}\text { Number of family } \\
\text { members }\end{array}$} & \multirow[t]{3}{*}{$\begin{array}{l}\mathrm{X}^{2}=0.09 \\
\mathrm{P}=0.955\end{array}$} \\
\hline $3-4$ & 76 & 38.6 & 49 & 39.5 & 18 & 40.9 & 143 & 39.2 & \\
\hline $5-6$ & 121 & 61.4 & 75 & 60.5 & 26 & 59.1 & 222 & 60.8 & \\
\hline \multicolumn{9}{|l|}{ Number of rooms } & \multirow{3}{*}{$\begin{array}{l}X^{2}=11.627 \\
P=0.020^{*}\end{array}$} \\
\hline $1-2$ & 21 & 10.7 & 15 & 12.1 & 8 & 18.2 & 44 & 12.1 & \\
\hline $3-4$ & 142 & 72.1 & 90 & 72.6 & 21 & 47.7 & 253 & 69.3 & \\
\hline
\end{tabular}


The Body Mass Index and Menstrual problems among Adolescent Students

\begin{tabular}{|c|c|c|c|c|c|c|c|c|c|}
\hline 5 or more & 34 & 17.2 & 19 & 15.3 & 15 & 34.1 & 68 & 18.6 & \\
\hline $\begin{array}{l}\text { Crowding index } \\
\text { (person/room) }\end{array}$ & & & & & & & & & \multirow[t]{5}{*}{$\begin{array}{l}\mathrm{F}=0.409 \\
\mathrm{P}=0.665\end{array}$} \\
\hline 1 or less & 5 & 2.5 & 0 & 0.0 & 2 & 4.5 & 7 & 1.9 & \\
\hline More than 1 & 192 & 97.5 & 124 & 100 & 42 & 95.5 & 358 & 98.1 & \\
\hline Min-Max & \multicolumn{2}{|c|}{$1.0-6.0$} & \multicolumn{2}{|c|}{$1.0-6.0$} & \multicolumn{2}{|c|}{$0.7-0.6$} & \multicolumn{2}{|c|}{$0.7-6.0$} & \\
\hline Mean \pm SD & \multicolumn{2}{|c|}{$2.5 \pm 1.0$} & \multicolumn{2}{|c|}{$2.5 \pm 1.0$} & \multicolumn{2}{|c|}{$2.3 \pm 1.0$} & \multicolumn{2}{|c|}{$2.5 \pm 1.0$} & \\
\hline
\end{tabular}

$\mathrm{X}^{2}$ : Chi-Square test

F: ANOVA test

*significant at $\mathbf{P} \leq \mathbf{0 . 0 5}$

Table (6): Shows relationship between socio-demographic characteristics of the studied adolescent girls and their body mass index" BMI" of There was statistical difference between family income and number of rooms $(\mathrm{P}=0.033, \mathrm{P}=0.020)$ respectively, of adolescent girls and their body mass index.

\section{Discussion}

Menstruation is a unique female phenomenon, It defines the start and end of reproductive potential (17) furthermore it is considered as indicator of women's health, so adolescent girls need to have an understanding of menstruation pattern and the factors that may attribute in menstrual disorders or changes like age, weather, activities and body mass index to increase their understanding of menstrual criteria, appropriate management for it and clarify the ignorance of menstruation issues (18). Based on the previous idea the research team designed the present study, which aimed to assess the relationship between Body Mass Index and menstrual problems among adolescent girls.

In the present study, two third of the adolescent girls had age of menarche ranged from 11- to $<14$ years. With the mean age at menarche of $12.8 \pm 1.06$ years. Dars et al., 2014 ${ }^{(8)}$ reported that $67.33 \%$ of the girls had their first menstrual period between the age of 11 and 13 All the girls had experienced menarche by the age of 16 years.

In line with this mentioned that the age of onset of menarche is generally between 11-15 years. Slight variations in the age of menarche may occur according to the nutritional status, hereditary pattern, and climate difference (19).other study reported that the delayed of menarche in girls had poor nutrition and earlier in girls with high-energy intake. This study is similar with a study conducted to determine the prevalence and pattern of menstrual symptoms among 352 nursing students in Beirut, Lebanon, which reported age of menarche, was 14 years for $23.3 \%$ and the he mean menarche age was 13.2 (SD 1.4) years (6).

In the present, study more than one third of adolescent girls had irregular menstrual cycle. $45.0 \%$ had little amount of menstrual blood and $16.3 \%$ had menorrhagia (profuse bleeding). Partially equal percentage of participants suffered from long duration and long interval of menstrual cycle (27.0\% and $26.2 \%$ respectively). The finding is in congruence with the study conducted in Beirut, Lebanon, (6), where the prevalence of irregular menstrual cycle, polymenorhhea, oligomenorrhea, secondary amenorrhea and menorrhagia was $59.4 \%, 37.5 \%, 19.3 \%, 5.1 \%$ and $11.7 \%$ respectively.

Furthermore, and in agreement with these present study findings, Dars et al $2014^{(8) .}$ In respect of regularity of menstrual cycle, it revealed that it was regular in three hundred and five (76\%) girls, whereas ninety-six (24\%) had irregular cycle .Moreover Lee $2006^{(20)}$ reported: After menarche, common menstrual abnormalities that the female adolescent may encounter include dysmenorrhea, irregularities in menstrual flow and premenstrual symptoms. $75 \%$ of girls experience some problems associated with menstruation.

Variations for interval between cycle and extent of flow observed as a type of menstrual irregularity in a study from adolescent girls in port said indicated that $24.6 \%$ and $26.2 \%$ of them encountered shorter $(<21$ )and longer cycles ( $>35$ days), respectively . and there was a statistical significant correlation between their body mass index" BMI" and short \& long interval menstrual cycle ( $\mathrm{P}=0.001)$. in support to our findings (21, 18) found that, positive correlation between body mass index and length of menstruation $(r=0.313)$. Additionally there is positive correlation between BMI \& PMS. In congruence with this, Mari \& Rvlaid 2005 ${ }^{(22)}$ emphasized that; one of the principal factors for the cycle regularity is bodyweight. But, in the study done by Bassi et al 2015 (23) reports, observed 6.6\% and 5.6\% of the participants in the short and long menstrual periods respectively\& No significant correlation could be drawn between cycle interval and BMI. In the first two years after menarche, the Variations in cycle length and duration are a common mainly due to anovulation (24).

Our study concluded that, (45.0\%) subjects had excessive amount of blood flow, $16.3 \%$ experienced little amount of blood flow and there was a statistically significant relationship observed between BMI and amount of menstrual blood flow. Heavy flow periods make females potentially more susceptible for iron deficiency anemia, which can be avoided by iron supplementation (25). In congruence with the foregoing, other studies reported that there was a statistically significant relationship observed between BMI and menstrual flow $(23,8)$. 
Menstrual disorders are a common problem in adolescents. These disorders are often the source of anxiety for the adolescents and their families and affects more than $50 \%$ of the menstruating women (26). As regards present of premenstrual syndrome, the majority of girls $(82.8 \%)$ had premenstrual syndrome, while (56.8\%) of them had physical symptoms as (colic-back pain-headache and exhaustion); less than half (43.6\%) had moderate severity of premenstrual symptoms. As well as there was statistical difference between the severity of premenstrual symptoms of adolescent girls and their body mass index" BMI" (P= 0.007).Results similar to these current study findings were also reported in a study in Hossain et al 2011\& Kavitha.2014 ${ }^{(27,28)}$ the majority $(72.30 \%)$ of the girls have premenstrual symptoms. Furthermore, and in agreement with these present study findings (29) reported that premenstrual symptoms were significantly more common among girls who were overweight, and did not do regular physical activity. There were some studies recognized that there is positive correlation between BMI \& PMS. (21, 18, 22), Furthermore, (30) clarified that Almost $75 \%$ of their subject indicated having physical symptoms, such as breast tenderness, headaches, joint/ muscle pain, bloating and weight gain and Overall, $91 \%$ had at least one symptom of any degree of severity. In addition, $6.4 \%$ reported severe interference of at least one symptom.

In line with this Kavitha. $2014{ }^{(28)}$ Premenstrual symptoms impact on daily life activities of the adolescent girls which it's a major causes of inability to concentrate on their work or studies, class or school absenteeism, inability to perform in their academic activities like physical training. So menstrual disturbance can be considered as one of the major health problems of female students and requires attention, so it is necessary to assessment abnormal menstrual patterns through adolescence and giving health education order to relieve to enhance adolescent student girls quality daily life activities during menstrual periods, lower the risks for future diseases. (31) Added the assessment of menstrual cycle is conceder as an additional vital sign

The anthropometric measurements help to confirm an adolescent's healthy growth and development, or to identify early a potential nutritional or health problem, also is particularly important because it acts as a tool for monitoring and evaluating the hormone-mediated changes in growth and reproductive maturation during this phase of life. Body mass index (BMI) is a commonly used anthropometric measurement to estimate the indices of underweight/overweight) of adolescents and adults (32), as well as the Body Mass Index (BMI) ranged between 18.3-33.9, (53.8\%) were normal BMI, Almost half of the studied adolescents were overweight and obese (33.9\% and $12.0 \%$ respectively) in our study. Were quite high, compared to findings of other studies. Goyal et al., $2010^{(33)}$ found that prevalence of overweight and obesity in Indian adolescent school going children was found to be $9.2 \%$ and $1.5 \%$ respectively. A study conducted in Brazil showed that $7.3 \%$ were overweight and $4.5 \%$ were obese among the adolescent schoolchildren. Results similar to these current study findings were also reported in a study by Lakkawar, $2014^{(2)}$ Overweight and obesity was found in $29.5 \%$ of the cases, $11 \%$ were underweight and $40.5 \%$ were of normal weight.

The present study results showed There was statistical difference between family income and number of rooms $(\mathrm{P}=0.033, \mathrm{P}=0.020)$ respectively, of adolescent girls and their body mass index. This result may be that the families with a high economic status high intake of food and had more activity saving devices such as televisions,computers, video $\mathrm{CD}$ players and automobiles which may reflect physical inactivity ,In congruence with this (Dars $2014(8)$ who reported A statistically significant relationship was found between BMI and social class $(\mathrm{P}<0.001)$ Additional, Wronka 2013 (34) reported that the Students from families of high socioeconomic status slightly more often estimated their weight status correctly than students with average and low status. In congruence with the foregoing In the developed countries, a high socio-economic status is correlated with a lower BMI, and girls of high socio-economic status overestimate their body weight by the WHO standards more often than women of low status. According to research conducted among New Zealanders, low socio-economic status is associated with weight underestimation (34).

\section{Conclusion}

Based on the result current study concluded that, There was statistical deference between the BMI and irregular menstrual cycle, oligomenorrhea, polymenorrhea and hypomenorrhea and hypermenorrhea $(\mathrm{P}=0.0001$, $0.001,0.05$ respectively). Likewise, there was statistical deference between the BMI and severity of premenstrual syndrome and excess body hair $(\mathrm{P}=0.007,0.03$ respectively). BMI play a very important role for menstrual cycle regularity. Therefore, adolescents have to give healthy $\&$ balance nutrition leads to maintain the normal BMI and regulate their menstrual cycle.

\section{Recommendations}

Lifestyle modification and nutritional counseling for female students could alleviate menstrual problems. It will not only improve the girls current health, sense of well-being and overall quality of life but may also lower her risks for future disease and ill health after proper advice about diet and exercise. Promoting healthy eating habits and maintaining normal \& optimal BMI should improve menstrual health. Further research in nutritional pattern in adolescents can be done. 


\section{References}

[1]. Kulkarni M., Durge PM.,(2011): Reproductive Health morbidities among adolescent girls: Breaking the silence. Ethno Med; Vol. 5(3):165-168.

[2]. Lakkawar N, Jayavani R., Arthi N, Alaganandam P, Vanajakshi N 2014: A Study of Menstrual Disorders in Medical Students and its Correlation with Biological Variables. Sch. J. App. Med. Sci., 2014; 2(6E):3165-3175, ISSN 2320-6691 (Online), ISSN 2347-954X (Print).

[3]. Lambert-Messerlian, G., (2011): First assessment of menstrual cycle function and reproductive endocrine status in Samoan women. Human Reproduction (Oxford, England), 26: 2518-2524.

[4]. Ibáñez, L., Abel lopez-Bermejo and Marta Diaz, (2011): Early Metformin therapy (age 8-12 years) in girls with precocious pubarche to reduce hirsutism and organ excess and oligomenorrhea in adolescence.

[5]. Thapa1 B., Shrestha T. (2015): Relationship between Body Mass Index and Menstrual Irregularities among the Adolescents, International Journal of Nursing Research and Practice Vol. 2 No. 2 (2015) July_December; 2350-1324. Available At www.uphtr.com/issue.../2015\%20i2,\%20v2\%203\%20Ms\%20Binu.pdf

[6]. Karout S., Hawai M., and Altuwaijri S.,(2012): Prevalence and pattern of menstrual disorders among Lebanese nursing students, WHO,18:4. E M H J Available from: http://www.emro.who.int/emh-journal/ eastern-Mediterranean-healthjournal/home.htm.

[7]. Chang P J.,(2009): Risk factors on the menstrual cycle of healthy Taiwanese college nursing students. Australian and New Zealand Journal of Obstetrics and Gynaecology, 49:689-694.

[8]. Dars S, Sayed K, Yousufzai Z. (2014): Relationship of menstrual irregularities to BMI and nutritional status in adolescent girls. Pak J Med Sci;30(1):140-144.doi: http://dx.doi.org/10.12669/pjms.301.3949).

[9]. WHO (2011):Canadian health measures survey 2009-2011.

[10]. Mohite RV1*, Mohite VR2, Kumbhar SM1, Ganganahalli (2013): Common Menstrual Problems among Slum Adolescent Girls of Western Maharashtra, India JKIMSU, Vol. 2, No. 1, Jan-June 2013.

[11]. Aref N.,Rizwan F., Abbas MM.(2015): Frequency of Different Menstrual Disorders among Female Medical Students at Taif Medical College, World Journal of Medical Sciences Vol. 12, No. (2): 109-114

[12]. CAPMAS, Central Agency of Public Mobilization and Statistical (2012): Estimated and projections of Egyptian population. Books of census and statistics. Detailed results.

[13]. Carlson KJ, Eisenstat SA, Ziporyn T (2004): The new Harvard guide to women's health. Harvard, Massachusetts, Harvard University Press, 384 .

[14]. Zaitoun, m. (2013): Gynecology, Zagazig Medical Book ,P. 72

[15]. Park K. Park.s. (2010): Textbook of Preventive and Social Medicine, 20th ed. Banarsidas Bhanot publishers Jabalpur: p347.

[16]. World Health Organization WHO. (2004): Body Mass Index Classification: WHO Bulletin, 2004.

[17]. Castillo-Martinez L, Lopez Alvarenga J, Villa A,and Gonzalez- J. (2003) :Menstrual cycle length disorders in 18- to 40y-old obese women. Nutrition; 19: 317-320.

[18]. Lu Z.(2006) :The relationship between menstrual attitudes and menstrual symptoms among Taiwanese women.J Adv Nurse; 33:621-8.

[19]. Journal of Clinical and Diagnostic Research, J Clin Diagn Res. (2013): Menstrual Abnormalities in School Going Girls - Are They Related to Dietary and Exercise Pattern? : Nov; 7 (11): 2537-2540.Published online 2013 Oct 10. doi: 10.7860/JCDR/2013/6464.3603.

[20]. Lee LK, Chen PCY, and Kaur J. (2006): Menstruation among adolescent girls in Malaysia: a cross-sectional school survey. Singapore Med J. Oct; 47(10): 869-74.

[21]. Samir N, Abd el Fattah H , Sayed E(2013): The correlation between body mass index and menstrual profile among nursing students of Ain Shams University .Egyptian nursing journal Vol 10, No 1.

[22]. Mari J and Rvlaid T.(2005) :The effect of gynecologic age ,body mass index and psychosocial environment on menstrual regularity among teenaged females Acta Obstet Gynecol Scand; 84: 645-649.

[23]. Bassi R., Sharma S., Saini A. and Kaur M (2015): Correlation of Menstrual Pattern with Body Mass Index in Young Female Students .J Phys Pharm Adv 5(2): 556-564 DOI: 10.5455/jppa.20150201093017.

[24]. Adams Hillard PJ (2002): Menstruation in young girls: a clinical perspective. Obstet. Gynecol., 99: 655-662.

[25]. Begum J, Hossain AM, Nazneen SA. (2009): Menstrual pattern and common menstrual disorders among students in Dinajpur College. Dinajpur Med Col J 2009; 2: 37-43

[26]. Derman O, Kanbur N. Tokur T,and Kutluk T. (2004): Premenstrual syndrome and associated symptoms in adolescence girls. Eur J Obstet Gynecol Reprod Boil; 116: 201-6.

[27]. Hossain.G., Sabiruzzaman M, Islam S, Hisyam R, Lestrel E, Kamarul T 2011:Influence of anthropometric measures and socio-demographic factors on menstrual pain and irregular menstrual cycles among university students in Bangladesh. Journal of ANTHROPOLOGICAL Science,Vol. 119(3), 239-246.

[28]. Kavitha.C \& Jamuna .B,(2014): Prevalence of dysmenorrohea and its impact on daily life activities in first and second year mbbs students. Int J Biol Med Res. 5(2): 4062- 4065.

[29]. Vani R., Veena S., Subitha L., Hemanth Kumar R., and Bupathy A.2013: Menstrual Abnormalities in School Going Girls - Are They Related to Dietary and Exercise Pattern?. J Clin Diagn Res. Nov; 7(11): 2537-2540.Published online 2013 Oct 10. doi: 10.7860/JCDR/2013/6464.3603

[30]. Tschudin S \& Bertea P \& Zemp E(2010): ORIGINAL ARTICLE Prevalence and predictors of premenstrual syndrome and premenstrual dysphoric disorder in a population-based sample. Arch Womens Ment Health (2010), Springer-Verlag 13:485-494, DOI 10.1007/s00737-010-0165-3.

[31]. American Academy of Pediatrics, Committee on Adolescence, American College of Obstetricians and Gynecologists, Committee on Adolescent Health Care (AAP\&ACOG) 2006:Menstruation in Girls and Adolescents: Using the Menstrual Cycle as a Vital SignAmerican Academy of Pediatrics, Committee on Adolescence, American College of Obstetricians and Gynecologists, Committee on Adolescent Health Care. November 2006, VOLUME 118 / ISSUE 5.

[32]. Yetubie M, Haidar J, Kassa H, and Fallon F.( 2010) : Socioeconomic and Demographic Factors Affecting Body Mass Index of Adolescents Students Aged 10-19 in Ambo (a Rural Town) in Ethiopia. Int J Biomed Sci. 6(4): 321-326.. PMCID: PMC3615286.

[33]. Goyal R, Shah V, Saboo B, Phatak S, Shah N, Gohel M, Prashad P, Patel S(2010): Prevalence of Overweight and Obesity in Indian Adolescent School Going children : Its relationship with Socioeconomic Status and Associated Lifestyle Factors. JAPI 2010; 58:151-158.

[34]. Wronka I, Teul I, Marchewka J,.( 2013): The influence of age at menarche on the prevalence of disorders of the menstrual cycle among healthy university students. Ann Acad Med Stetin.;59(2):94-8. 